\title{
Computed tomographic emphysema distribution: relationship to clinical features in a cohort of smokers
}

\author{
G. Mair*, J.J. Miller*, D. McAllister*, J. Maclay*, M. Connell\#, \\ J.T. Murchison ${ }^{\star}$ and W. MacNee*
}

ABSTRACT: Computed tomography (CT) scanning allows precise assessment of both the extent and distribution of emphysema. There has been little work on the relationship between the distribution of emphysema and clinical features of the disease. The current study investigated the association between clinical features and distribution of emphysema.

A total of 129 patients with smoking-related chronic obstructive pulmonary disease underwent CT assessment of the extent and distribution of their emphysema (core/rind and upper/lower zone predominance).

Emphysema was found predominantly in the upper/core zone and this distribution was related to the extent of disease. Core predominance was associated with lower forced expiratory volume in one second ( $F E V_{1}$ ), $F_{E V}$ /forced vital capacity ratio and body mass index (BMI); and with higher BODE (BMI, airflow obstruction, dyspnoea and exercise capacity) index and Medical Research Council dyspnoea score. Upper-zone predominance was associated with female sex and an increased total St George's Respiratory Questionnaire score. Using multiple linear regression age, sex and whole lung emphysema severity were independently associated with core/rind distribution, while sex and whole lung emphysema severity were independently related to upper/ lower distribution.

Distribution of emphysema related best to clinical features when divided into core/rind predominance. However, the effects were not independent of the extent of emphysema. Increased age and female sex were related to disease distribution independent of emphysema severity. These findings may be related to differences in development of emphysema.

KEYWORDS: Chronic obstructive pulmonary disease, distribution, emphysema, low attenuation areas, multi-slice computed tomography

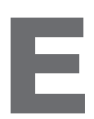
mphysema causes airflow limitation in chronic obstructive pulmonary disease (COPD) through destruction of the alveolar walls, resulting in decreased lung elastic recoil and airway collapse [1]. Emphysema leads to a marked decrease in lung tissue volume and an increase in airspace volume. These changes can be demonstrated by computed tomography (CT) scanning as regions of reduced lung density [2].

Advances in CT scanning and specifically designed software now allow precise assessment of the extent of emphysema. Areas of the lung with a density below a given threshold (commonly -950 Hounsfield units (HU)) are designated as emphysematous. This technique has been validated against pathology $[3,4]$ and pulmonary function $[5,6]$. In addition, the technology can be used to assess the distribution of emphysematous disease, an approach that has been utilised in assessing patients for (and in the outcomes of) lung volume reduction surgery [7, 8] and also in monitoring changes in emphysema longitudinally in $\alpha_{1}$-antitrypsin-deficient patients [9]. The distribution of the parenchymal damage varies between individuals, but the reasons for this are not known. This heterogeneity is reflected in the wide variation in clinical features seen. Despite this, there is a paucity of studies investigating how differences in the distribution of emphysema relate to different clinical features among patients with COPD $[10,11]$.

In the present study, patients were categorised according to the distribution of their emphysema. It was hypothesised that clinical features vary between patients with different distributions. It was hoped that by using $\mathrm{CT}$, patterns of disease

\section{AFFILIATIONS}

${ }^{*}$ Medical Research Council Centre for Inflammation Research, Queen's Medical Research Institute, University of Edinburgh, and

"Depts of Medical Physics and -Radiology, Royal Infirmary of Edinburgh, Edinburgh, UK.

CORRESPONDENCE

W. MacNee

ELEGI Colt Laboratory,

Medical Research Council Centre for Inflammation Research,

Queen's Medical Research Institute, University of Edinburgh, 47 Little France Crescent, Edinburgh, EH16 4TJ, UK. Fax: 441312426582

E-mail: w.macnee@ed.ac.uk

Received:

July 222008

Accepted after revision:

September 232008

SUPPORT STATEMENT

The present study was funded by the National Institutes of Health (Bethesda, MD, USA; grant RFA-HL02-005), the Norman Salvesen Emphysema Research Trust (Edinburgh, UK) and Pfizer (Sandwich, UK).

\section{STATEMENT OF INTEREST}

Statements of interest for W. MacNee and the study itself can be found at www.ersjournals.com/misc/

statements.shtml

European Respiratory Journal

Print ISSN 0903-1936

Online ISSN 1399-3003 
correlating with clinical severity could be identified. To the current authors' knowledge, other than with spirometry, such comparisons have not previously been made.

\section{METHODS}

\section{Study patients}

Current and ex-smokers with a clinical history consistent with COPD, defined by: symptoms of cough; sputum production and/or breathlessness; and a >10-pack-yr smoking history were recruited from primary care and through a respiratory outpatient clinic at the Royal Infirmary of Edinburgh (Edinburgh, UK). Diagnosis was confirmed with a postbronchodilator forced expiratory volume in one second (FEV1)/forced vital capacity (FVC) ratio $<70 \%$ [1]. Patients were studied when clinically stable, $\geqslant 6$ weeks post-exacerbation. Subjects with other respiratory conditions, systematic inflammatory diseases or prescribed regular oral corticosteroids were excluded. In total, 129 patients were recruited. All studies were performed with the approval of Lothian Regional Ethics Committee (Edinburgh, UK) and written informed consent was obtained from all subjects.

\section{Study design}

A structured questionnaire was administered by trained healthcare staff to record baseline characteristics, including past medical history and smoking status. Medical Research Council (MRC) chronic bronchitis score, MRC dyspnoea score and the results of the St George's Respiratory Questionnaire (SGRQ) were recorded. Exacerbation frequency was assessed by patient recall over a 1-yr period. An exacerbation was defined as an increase in symptoms requiring a course of corticosteroids or antibiotics. Corroboration was obtained in most cases by review of the patient's hospital and/or general practitioner (GP) notes.

Patients performed a 6-min walk according to American Thoracic Society guidelines [12]. Spirometry was performed in triplicate (Vitalograph ${ }^{\circledR}$, Ennis, Ireland) with reversibility to salbutamol (2.5 mg nebulised). Height and weight were measured to calculate body mass index (BMI). BMI, airflow obstruction, dyspnoea and exercise capacity (BODE) index was calculated as described by CeLLi et al. [13].

\section{CT protocol}

Study subjects underwent a low-dose quantitative thoracic CT scan at full inspiration. Patients were coached to achieve total lung capacity. No intravenous contrast was administered. A Toshiba Aquilion 16-slice CT scanner (Toshiba Medical Systems, Tokyo, Japan), was used with the following parameters: $135 \mathrm{kV}, 40 \mathrm{~mA}$, rotation time $0.5 \mathrm{~s}, 16 \times 1 \mathrm{~mm}$ collimation, pitch 1.45 , reconstructed at $2.5-\mathrm{mm}$ intervals with $5-\mathrm{mm}$ thick slices and at 1-mm intervals with 1-mm slices, and FC-03 filter. Slices were reconstructed to maximise the data available for analysis. All slices were used in the quantitative analysis. The HU for air was recalibrated using a method similar to that described by STOEL and STOLK [14] to correct for the air offset in Toshiba CT scanners (about $-985 \mathrm{HU}$ instead of the nominal $-1,000 \mathrm{HU}$ with the filter used). All CT scans were reviewed by an experienced chest radiologist (J.T. Murchison). On visual assessment, any CT scans with other lung conditions (e.g. bronchiectasis and interstitial lung disease) resulted in exclusion of the patient from the study. Incidental lung nodules were followed with interval CT scans according to the Fleischner Society recommendations [15]. None of these nodules were subsequently thought to represent a cancer.

\section{CT measurements}

The number of pixels below -950 HU was used to quantify low-attenuation areas (LAA) as a measure of emphysema. Software was developed to calculate the percentage of pixels below this threshold (LAA-950) from the total number in each CT scan. To estimate the distribution of LAA, total lung volume was divided equally into upper and lower, and also core and rind regions. The boundary between the upper and lower regions was the CT slice that divided total lung volume into two equal regions, while the peripheral $50 \%$ of lung area on each CT slice was defined as the rind region (fig. 1). This process was automated using an erosion algorithm originally described by HARALICK et al. [16]: in each cycle, one layer of pixels at the outer boundary of the lung is removed until 50\% of the initial lung area remains. The percentage of LAA in each region (core/rind and upper/lower) was then calculated from the total. This created two continuous variables for the
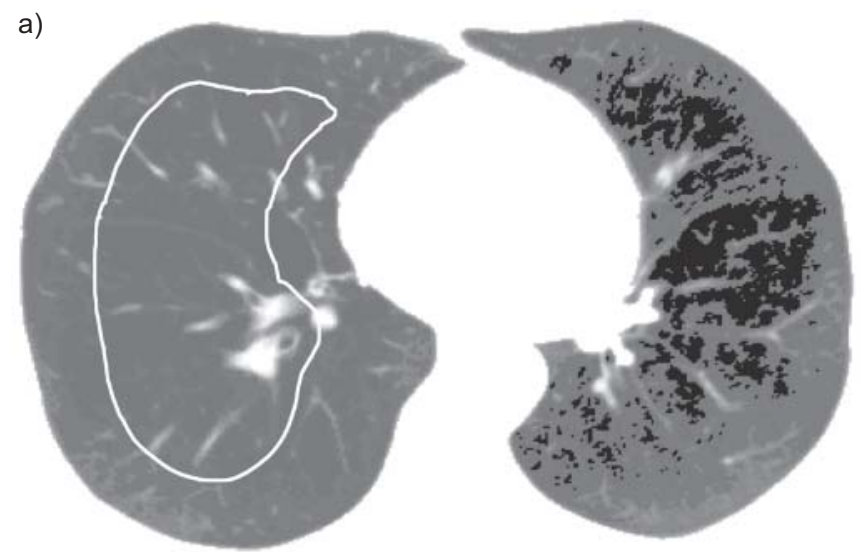

b)
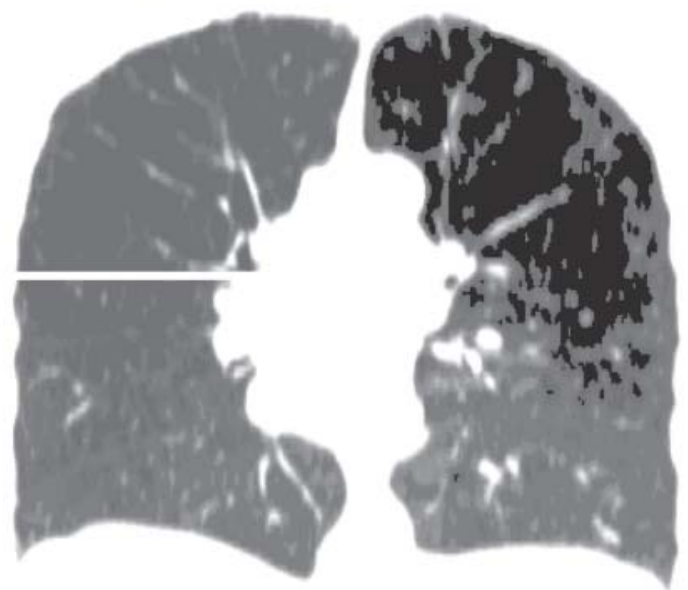

FIGURE 1. Defining emphysema distribution. All patients were classified both as core or rind predominant and as upper- or lower-zone predominant. White lines show the definition of the a) core versus rind and b) upper versus lower zones. The percentage of low-attenuation areas below -950 Hounsfield Units (LAA-950; shaded in black) in each zone was calculated from the total number of LAA-950. Where $>50 \%$ LAA-950 occurred in any zone, this was considered to indicate predominance. The patient illustrated has upper/core predominance. 
distribution: i.e. $0-100 \%$ of LAAs in the upper zone and 0 $100 \%$ of LAAs in the core zone. Each patient was then categorised as upper- or lower-zone predominant, and also as core or rind predominant, when $>50 \%$ of LAAs were in any distribution region. This allowed classification into one of four groups: upper/rind, upper/core, lower/rind and lower/core predominant.

\section{Statistical analysis}

The \% LAA-950 variable had a skewed distribution and thus was log-transformed. Other non-normally distributed variables were analysed using nonparametric tests.

Pearson's correlation coefficient was used to determine relationships between normally distributed or log-transformed variables; otherwise, Spearman's rank test was used. Independent-sample t-tests were utilised in comparing means between groups with dichotomous data. One-way ANOVA was used to compare the four distribution groups, with Tukey's post hoc testing used to identify significant differences. Only comparisons with one consistent variable were analysed, as these would provide useful information. For example, upper/core compared with lower/core was analysed, while upper/core compared to lower/rind was not.

Multiple linear regression modelling was used to test for independent associations between clinical features and both the extent and distribution of emphysema. Variables found to be significant on univariate analysis, and potential confounders,

\begin{tabular}{|c|c|c|}
\hline TABLE 1 & \multicolumn{2}{|c|}{$\begin{array}{l}\text { Demographic data, clinical features and } \\
\text { computed tomography results }\end{array}$} \\
\hline \multicolumn{2}{|l|}{ Patients n } & 129 \\
\hline \multicolumn{2}{|l|}{ Sex male } & $85(66 \%)$ \\
\hline \multicolumn{2}{|l|}{ Age yrs } & $67 \pm 8$ \\
\hline \multicolumn{2}{|c|}{$\mathrm{FEV}_{1} \%$ pred } & $52 \pm 19$ \\
\hline \multicolumn{2}{|l|}{ FVC \% pred } & $82 \pm 20$ \\
\hline \multicolumn{2}{|l|}{$\mathrm{FEV}_{1 / \mathrm{FVC}} \%$} & $49 \pm 12$ \\
\hline \multicolumn{2}{|l|}{$\mathrm{Sa}, \mathrm{O}_{2} \%$} & $96 \pm 1.9$ \\
\hline \multicolumn{2}{|c|}{ Smoking history pack-yrs } & $45 \pm 20$ \\
\hline \multicolumn{2}{|c|}{$B M I \mathbf{k g} \cdot \mathbf{m}^{-2}$} & $26 \pm 6$ \\
\hline \multicolumn{2}{|c|}{ 6-min walk distance $\mathrm{m}$} & $361 \pm 118$ \\
\hline \multicolumn{2}{|c|}{ SGRQ total } & $47 \pm 20$ \\
\hline \multicolumn{2}{|c|}{ BODE index } & $4 \pm 2$ \\
\hline \multicolumn{2}{|c|}{ Exacerbation frequency $\mathrm{yr}^{-1}$} & $2(1-3)$ \\
\hline \multicolumn{2}{|c|}{ MRC dyspnoea score } & $3 \pm 1$ \\
\hline \multicolumn{2}{|c|}{ MRC bronchitis score } & $1=63 / 129(53 \%)$ \\
\hline \multicolumn{2}{|c|}{ Current smoker n } & $40(31 \%)$ \\
\hline \multicolumn{2}{|c|}{$\%$ LAA-950 } & $5.5(1.6-17.5)$ \\
\hline \multicolumn{2}{|c|}{ Upper \% below -950 HU\# } & $57 \pm 23$ \\
\hline \multicolumn{2}{|c|}{ Core \% below -950 $\mathrm{HU}^{\#}$} & $54 \pm 15$ \\
\hline
\end{tabular}

Data are presented as $n(\%)$, mean \pm SD or median (interquartile range), unless otherwise stated. FEV1: forced expiratory volume in one second; \% pred: \% predicted; FVC: forced vital capacity; $\mathrm{Sa}_{2} \mathrm{O}_{2}$ : arterial oxygen saturation; $\mathrm{BMI}$ : body mass index; SGRQ: St George's Respiratory Questionnaire; BODE: BMI, airflow obstruction, dyspnoea and exercise capacity; MRC: Medical Research Council; LAA-950: low-attenuation areas below -950 Hounsfield Units (HU). ${ }^{*}$ : calculated as $100 \times$ (number of pixels below $-950 \mathrm{HU}$ in relevant zone)/(total number of pixels below $-950 \mathrm{HU}$ ) were included in these multiple regression models. Some collinearity was found between FEV1, BODE index and MRC dyspnoea score, but this had little effect on the results and so these variables have been left in the analysis for completeness.

In all statistical analyses, a p-value $<0.05$ was regarded as statistically significant.

\section{RESULTS}

The patient characteristics demonstrate a wide range of airflow limitation, 6-min walking distance, total SGRQ score and BODE index, reflecting the spectrum of disease encountered in clinical practice (table 1). Table 1 also shows the extent of emphysema, given as the total percentage LAAs (\% LAA-950), and how these are distributed as continuous variables. The means for both core/rind and upper/lower distributions were each a little more than $50 \%$.

\section{Emphysema distribution}

For most patients, there was a predominance of LAAs in upper, core regions (64\% had LAAs in the upper region, $66 \%$ in the core and $48 \%$ both). The severity of emphysema in the whole lung (log \% LAA-950) was associated with a higher percentage of emphysema in the upper $(r=0.23, p=0.008)$ and core $(r=0.69, p<0.001)$ regions. When the two distributions of emphysema were correlated, percentage upper-zone distribution was significantly related to percentage core distribution $(\mathrm{r}=0.28, \mathrm{p}=0.001)$, as shown in figure 2 .

\section{Correlation of emphysema with clinical features}

On univariate analysis (table 2), several clinical features were associated with the extent of emphysema measured by CT. In nearly all cases, those same clinical features were significantly related to an increased percentage of core disease. Increased core distribution was associated with lower FEV1 $(r=-0.35$, $\mathrm{p}<0.001)$, FEV1/FVC ratio $(\mathrm{r}=-0.52, \mathrm{p}<0.001)$ and BMI $(\mathrm{r}=-0.24$, $\mathrm{p}=0.006)$; and with higher BODE index $(\mathrm{r}=0.30, \mathrm{p}=0.003)$ and MRC dyspnoea score $(r=0.27, p=0.002)$. An increase in the upper-zone distribution of emphysema was associated with female sex (mean 11.4\% greater, $\mathrm{p}=0.006$ ) and a higher total SGRQ score $(\mathrm{r}=0.18, \mathrm{p}=0.039)$.

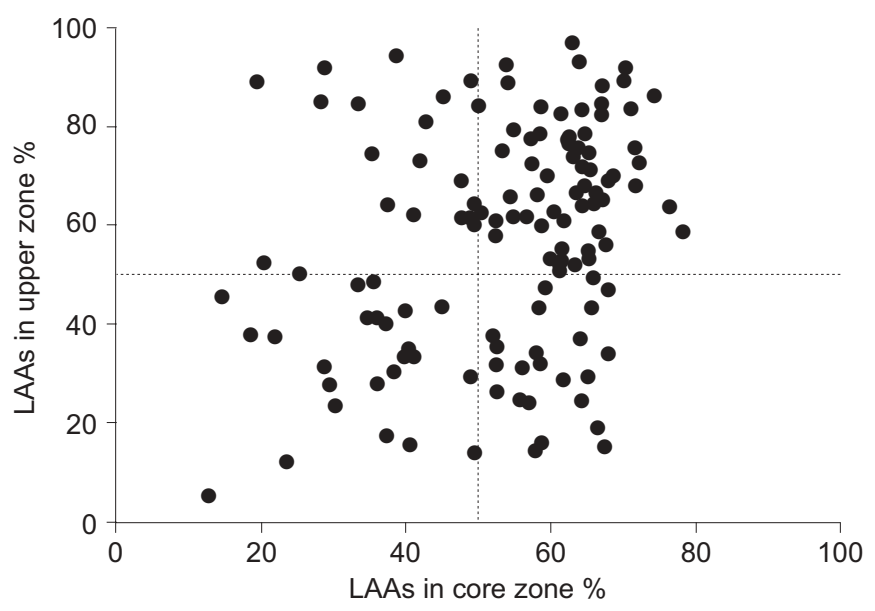

FIGURE 2. Distribution of low-attenuation areas (LAAs) on computed tomography when divided into core/rind and upper/lower zones. 
TABLE 2 Relationship between extent and distribution of computed tomography-measured emphysema and clinical features

Correlation of extent of emphysema with log \% LAA-950

Distribution of emphysema

Correlation with \% core zone

Correlation with \% upper zone

\begin{tabular}{|c|c|c|c|}
\hline Age yrs & 0.05 & 0.07 & -0.09 \\
\hline Sex & 0.32 & -5.01 & $-11.4^{+}$ \\
\hline FEV $1 \%$ pred & $-0.52^{\star \star \star}$ & $-0.35^{\star \star \star}$ & -0.01 \\
\hline FVC \% pred & -0.04 & 0.11 & 0.03 \\
\hline FEV $1 / F V C \%$ & $0.70 \star \star \star$ & $-0.52 * \star \star$ & -0.03 \\
\hline Smoking history pack-yrs & -0.06 & -0.03 & -0.08 \\
\hline $\mathrm{BMI} \mathbf{k g} \cdot \mathrm{m}^{-2}$ & $-0.48^{\star \star \star}$ & $-0.24^{+}$ & -0.03 \\
\hline 6-min walking distance $\mathrm{m}$ & 0.04 & -0.15 & -0.07 \\
\hline SGRQ total & 0.20 & 0.17 & $0.18^{\S}$ \\
\hline BODE index & $0.35^{f}$ & $0.30^{\# \#}$ & 0.08 \\
\hline Exacerbation frequency ${ }^{\#}$ & 0.09 & 0.04 & -0.10 \\
\hline MRC dyspnoea score & 0.24 & $0.27^{\bullet \oplus}$ & 0.10 \\
\hline MRC bronchitis score & 0.18 & 2.10 & 1.43 \\
\hline $\mathrm{Sa}, \mathrm{O}_{2} \%$ & $-0.34^{++}$ & -0.16 & 0.09 \\
\hline
\end{tabular}

LAA-950: low-attenuation areas below -950 Hounsfield Units; FEV1: forced expiratory volume in one second; \% pred: \% predicted; FVC: forced vital capacity; BMI: body mass index; SGRQ: St George's Respiratory Questionnaire; BODE: BMI, airflow obstruction, dyspnoea and exercise capacity; MRC: Medical Research Council; Sa, $\mathrm{O}_{2}$ arterial oxygen saturation; ${ }^{*}$ : nonparametric test used; ${ }^{\bullet}$ : independent-sample t-test used (difference in means given). ${ }^{+}: p=0.006 ;{ }^{* \star *}: p<0.001 ;{ }^{\S}: p=0.039 ;{ }^{f}: p=0.022$; \#\# : $p=0.003 ;{ }^{\top}: p=0.002 ;{ }^{++}: p=0.011$. Only statistically significant $p$-values are given

a)
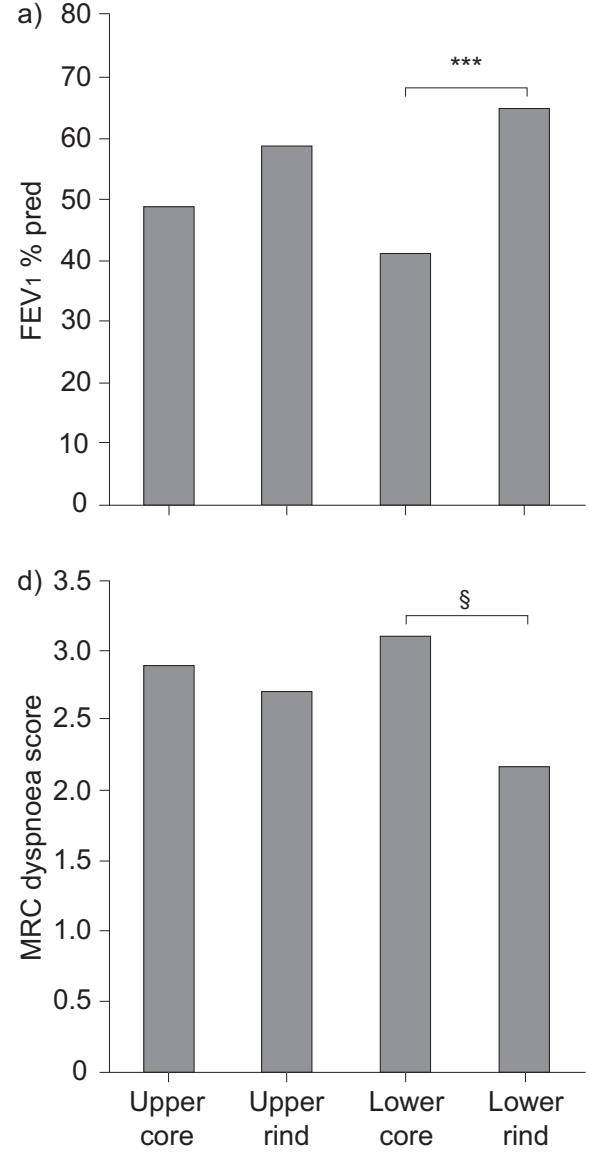

b) 80
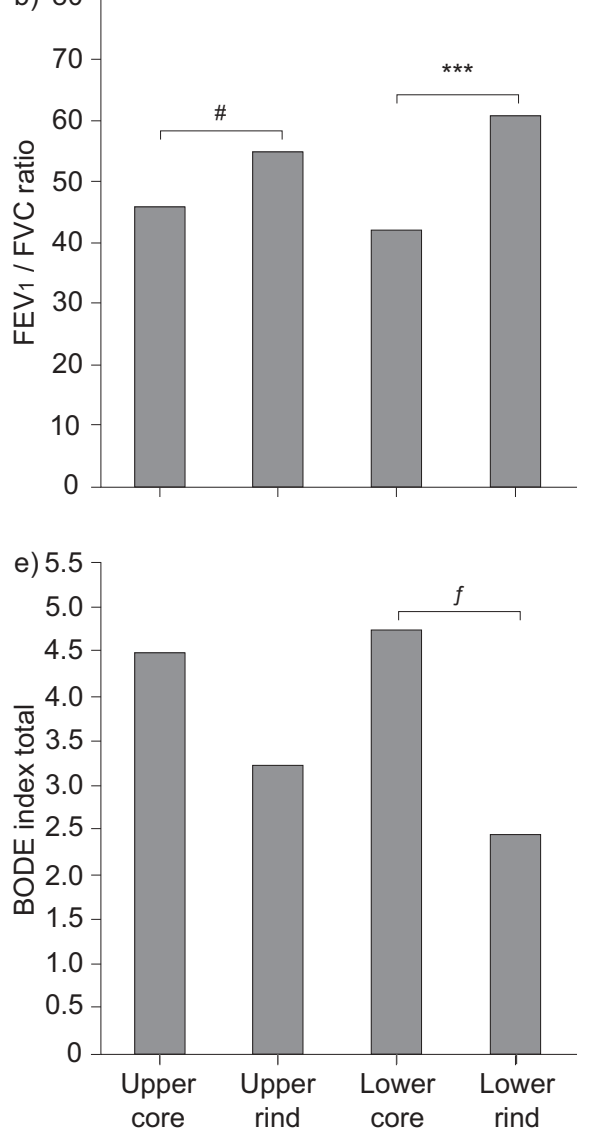

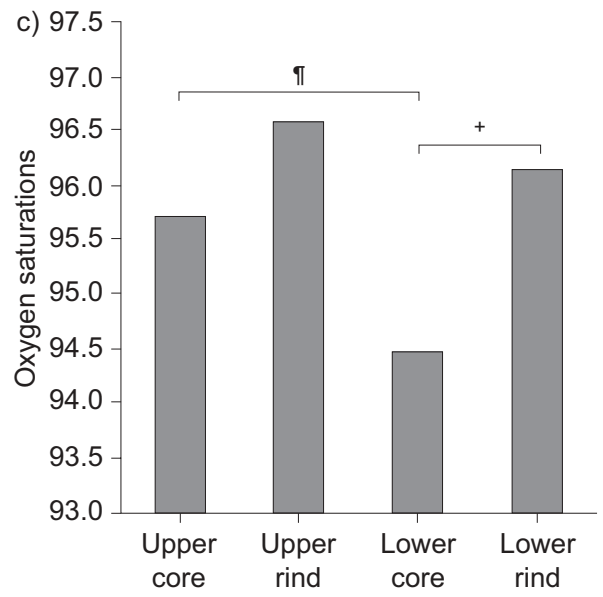

FIGURE 3. Results of ANOVA. Histograms represent: a) mean \% predicted (\% pred) forced expiratory volume in one second (FEV 1 ); b) FEV 1 / forced vital capacity (FVC) ratio; c) arterial oxygen saturations; d) Medical Research Council (MRC) dyspnoea score; and e) body mass index, airflow obstruction, dyspnoea and exercise capacity (BODE) index. \#: $p=0.007 ;$ ध: $p=0.027$; $\mathrm{p}=0.014 ;{ }^{\S}: \mathrm{p}=0.010 ;{ }^{f}: \mathrm{p}=0.012 ;{ }^{* * *}: \mathrm{p}<0.001$. 
TABLE 3 Multiple linear regression model of emphysema extent on clinical variables

\begin{tabular}{lccc} 
Model & Beta coefficient (95\% Cl) & Partial correlations & p-value \\
\hline Age & $-0.02(-0.05-0.02)$ & -0.09 & 0.380 \\
Sex & $0.46(-0.17-1.01)$ & 0.15 & 0.152 \\
BMI & $-0.09(-0.15--0.04)$ & -0.33 & 0.002 \\
FEV1 \% pred & $-0.04(-0.06--0.02)$ & -0.35 & 0.001 \\
BODE index & $-0.08(-0.25-0.10)$ & -0.09 & 0.387 \\
Sa, $\mathbf{O}_{2}$ & $-0.05(-0.22-0.11)$ & -0.07 & 0.524 \\
\hline
\end{tabular}

Overall result for the model: log percentage of low-attenuation areas below -950 Hounsfield Units $\left(r^{2}=0.33, p<0.001\right)$. Cl: confidence interval; BMI: body mass index FEV1: forced expiratory volume in one second; \% pred: \% predicted; BODE: BMI, airflow obstruction, dyspnoea and exercise capacity; Sa, $\mathrm{O}_{2}$ : arterial oxygen saturation

On comparing patients with predominantly upper/rind, lower/rind, upper/core or lower/core emphysema, \% predicted FEV1, FEV1/FVC ratio, arterial oxygen saturation $\left(\mathrm{Sa}_{\mathrm{a}} \mathrm{O}_{2}\right)$, MRC dyspnoea score and BODE index were found to be significantly different. Post hoc testing revealed that in all cases, lower-zone core-to-rind differences were significant, while only $\mathrm{Sa}_{1} \mathrm{O}_{2}$ differed between upper and lower zones (fig. 3).

Using multiple linear regression modelling, only BMI and FEV1 were significant and therefore independently related to the extent of emphysema (log \% LAA-950). In assessing distribution, age, sex and extent of emphysema were independently associated with core/rind, while only sex and extent of emphysema were independently related to upper/lower (tables 3-5).

\section{DISCUSSION}

CT assessment of COPD patients allows accurate measurement of emphysema extent and distribution. In a large cohort of 129 patients with COPD, the present authors have examined whether the extent and distribution of CT-measured emphysema relates to clinical features. This is the first time such comparisons have been made to clinical parameters other than spirometry.

As expected, several clinical features of COPD were significantly related to total lung emphysema severity (\% LAA-950) as measured using CT. Interestingly, when the distribution of emphysema is related to clinical features, core-to-rind differences in distribution are more significantly associated than upper-to-lower ones. Nearly all clinical features that correlate to total lung emphysema severity show significant relationships when distribution of emphysema is divided into core and rind. (Most notably, core emphysema is associated with a significant decrease in FEV1 \% pred, a higher BODE index, a higher MRC dyspnoea score and a lower BMI.) Two clinical features (SGRQ score and sex) were related to upper/lower emphysema predominance (upper zone predominance of emphysema is associated with an increased total SGRQ score, i.e. worse health status) and is more common in females. When viewed in a one-way ANOVA, it is apparent that differences in lower-zone core/rind distribution are most related to changes in clinical outcome. This finding is rather surprising, given that the majority of the current patients have upper/core disease and that the extent of emphysema is correlated with both upper-zone and core predominance. In other words, more severe upper-zone, core-predominant emphysema is found in the majority of the current patients, yet the more subtle lowerzone disease shows the best correlation with clinical features.

This does, however, agree with other work published on emphysema distribution. GURNEY et al. [17] found in a study of 59 smokers that severe upper-zone emphysema was less related to spirometry than milder lower-zone disease. Similarly, the current findings are in agreement with the only

\section{TABLE 4 Multiple linear regression model of core/rind emphysema distribution on clinical variables}

\begin{tabular}{lccc} 
Model & Beta coefficient $\mathbf{( 9 5 \% ~ C l )}$ & Partial correlations & p-value \\
\hline Age & $0.35(0.11-0.59)$ & 0.29 & 0.005 \\
Sex & $-9.52(-13.9--5.16)$ & -0.41 & $<0.001$ \\
Log \% LAA-950 & $7.18(5.73-8.62)$ & 0.72 & $<0.001$ \\
BMI & $0.15(-0.24-0.54)$ & 0.08 & 0.455 \\
FEV 1 \% pred & $1.10(-0.08-0.29)$ & 0.12 & 0.258 \\
BODE index & $0.33(-1.79-2.46)$ & 0.03 & 0.758 \\
MRC dyspnoea score & $1.52(-2.15-5.19)$ & 0.09 & 0.412 \\
\hline
\end{tabular}

Overall result for the model: core/rind distribution of emphysema $\left(r^{2}=0.62, p<0.001\right)$. Cl: confidence interval; LAA-950: low-attenuation areas below -950 Hounsfield Units; BMI: body mass index; FEV1: forced expiratory volume in one second; \% pred: \% predicted; BODE: BMI, airflow obstruction, dyspnoea and exercise capacity; MRC: Medical Research Council. 


\section{TABLE 5 Multiple linear regression model of upper/lower emphysema distribution on clinical variables}

\begin{tabular}{|c|c|c|c|}
\hline Model & Beta coefficient $(95 \% \mathrm{Cl})$ & Partial correlations & p-value \\
\hline Age & $-0.03(-0.54-0.47)$ & -0.01 & 0.904 \\
\hline Log \% LAA-950 & $3.47(0.92-6.03)$ & 0.24 & 0.008 \\
\hline SGRQ total & $0.14(-0.05-0.34)$ & 0.13 & 0.147 \\
\hline
\end{tabular}

two published papers that describe smoking-related emphysema (as distinct from $\alpha_{1}$-antitrypsin deficiency-related emphysema) distribution in terms of upper/lower and core/ rind predominance. NAKANO et al. [11] also found that core disease was related to disease severity (as measured by pulmonary function tests), with lower/core disease more related to spirometry, and upper/core to carbon monoxide transfer factor. HARAGUCHI et al. [10] found that centrally distributed emphysema had the strongest relationship to pulmonary function, and also that lower-zone disease related better than upper.

On multiple linear regression, only FEV1 and BMI were associated with the extent of emphysema (LAA-950), i.e. these are the only two clinical factors that actually relate to the CT-measured severity of emphysema in the current cohort. A similar outcome was observed in the distribution analyses: although a number of symptomatic features were associated with an increased percentage of core or upper zone disease on univariate analysis, after adjusting for confounding by emphysema severity and FEV1, only age and sex remained associated. Therefore, the current authors were unable to demonstrate that clinical features were related to differing distributions of emphysema in COPD.

The finding that upper-zone core disease was associated with emphysema severity was interesting. One possible explanation is that differences in mechanical forces in the lower and rind zones provide some protection to lung parenchyma, such that only those with more severe or advanced disease develop emphysema at these sites. The distribution analyses also demonstrate that females were most likely to have core disease in the upper zones, while increasing age was likewise associated with core predominance. These effects of age and sex were found to be independent of disease severity. It is possible then, that for most patients, smoking-related emphysema predominates in the upper/core region with increasing severity; while for females and those of increasing age, the disease may begin with a predominantly core distribution regardless of severity.

Such ideas point to differences in the development of emphysema. It might be suggested that distribution patterns are related to the underlying pathological phenotype. Traditionally, centrilobular and paraseptal emphysema were thought to have upper-lobe predominance and be more common in smokers, while panlobular emphysema was considered to predominate in the lower lobes in patients with $\alpha_{1}$-antitrypsin deficiency $[18,19]$.

Until recently, information on sex-related differences in emphysema has been limited. Results from the National Emphysema Treatment Trial showed that there is a core predominance of emphysematous disease in females: the authors postulated that sex differences in emphysema may be explained by an increased susceptibility of females to comparable degrees of cigarette smoke exposure [20].

The association of core distribution with increasing age may in some way be related to the normal age-related decline in lung function [21]. It is possible that this occurs predominantly in the core zones of the lung. However, pathological studies would be required to determine whether CT assessment of emphysema distribution in this way is related to disease subtype, while issues of susceptibility and age-related decline can only be resolved with longitudinal data.

\section{Study limitations}

The current study does have some limitations in design. Patient selection was opportunistic: those referred from primary care and attending a specialised clinic were recruited sequentially. Ideally, a random selection of patients from a COPD population would have been more appropriate, but the current authors believe that the cohort is nevertheless representative of the COPD population at large.

CT scanning was performed at maximal arrested inspiration and there is still some debate in the literature over the need for spirometric gating [14, 22-25]. A recent international workshop, however, concluded that this was unnecessary, particularly if scans are not compared longitudinally, as in the current study [26].

Assessment of exacerbation frequency was based on patient recall. This clearly has implications for accuracy, but in most patients, hospital and/or GP notes were used to corroborate.

In summary, a core predominant distribution of emphysema, particularly in the lower zones, shows the best relationship with clinical features. The current authors have demonstrated that assessing emphysema in this way not only relates well to spirometry, but also, as shown for the first time in the current study, to measures of functional status. It was not, however, possible to demonstrate that these associations are independent of the degree of emphysema, age or sex. Age and sex 
differences may be related to disease development but to determine whether emphysema distribution is merely a measure of severity or an independently related feature of the disease would require longitudinal studies.

\section{ACKNOWLEDGEMENTS}

The current authors would like to thank J.E. Barr and A. Deans, respiratory research nurses (Dept of Respiratory Medicine, Royal Infirmary of Edinburgh, UK), for their work in collecting the patient data used in the analyses.

\section{REFERENCES}

1 Global Initiative for Chronic Obstructive Lung disease (GOLD). Global strategy for the diagnosis, management, and prevention of chronic obstructive pulmonary disease. Bethesda, National Heart, Lung and Blood Institute/World Health Organization, 2006.

2 Goddard PR, Nicholson EM, Laszlo G, Watt I. Computed tomography in pulmonary emphysema. Clin Radiol 1982; 33: 379-387.

3 Hayhurst MD, MacNee W, Flenley DC, et al. Diagnosis of pulmonary emphysema by computed tomography. Lancet 1984; 2: 320-322.

4 Muller NL, Staples CA, Miller RR, Abboud RT. "Density Mask". An objective method to quantitate emphysema using computed tomography. Chest 1988; 94: 782-787.

5 Gould GA, Redpath AT, Ryan M, et al. Lung CT density correlates with measurements of airflow limitation and the diffusing capacity. Eur Respir J 1991; 4: 141-146.

6 Haraguchi M, Shimura S, Hida W, Shirato K. Pulmonary function and regional distribution of emphysema as determined by high resolution computed tomography. Respiration 1998; 65: 125-129.

7 Nakano Y, Coxson HO, Bosan S, et al. Core to rind distribution of severe emphysema predicts outcome of lung volume reduction surgery. Am J Respir Crit Care Med 2001; 164: 2195-2199.

8 Stolk J, Versteegh MIM, Montenij LJ, et al. Densitometry for assessment of effect of lung volume reduction surgery. Eur Respir J 2007; 29: 1138-1143.

9 Parr DG, Stoel BC, Stolk J, Stockley RA. Validation of computed tomographic lung densitometry for monitoring emphysema in $\alpha_{1}$-antitrypsin deficiency. Thorax 2006; 61: 485-490.

10 Haraguchi M, Shimura S, Hida W, Shirato K. Pulmonary function and regional distribution of emphysema as determined by high resolution computed tomography. Respiration 1998; 65: 125-129.

11 Nakano Y, Sakai H, Muro S, et al. Comparison of low attenuation areas on computed tomographic scans between inner and outer segments of the lung in patients with chronic obstructive pulmonary disease: incidence and contribution to lung function. Thorax 1999; 54: 384-389.
12 ATS Committee on Proficiency Standards for Clinical Pulmonary Function Laboratories. ATS statement: Guidelines for the six-minute walk test. Am J Respir Crit Care Med 2002; 166: 111-117.

13 Celli BR, Cote CG, Marin JM, et al. The body-mass index, airflow obstruction, dyspnea, and exercise capacity index in chronic obstructive pulmonary disease. $N$ Engl J Med 2004; 350: 1005-1012.

14 Stoel BC, Stolk J. Optimization and standardization of lung densitometry in the assessment of pulmonary emphysema. Invest Radiol 2004; 39: 681-688.

15 MacMahon H, Austin JHM, Gamsu G, et al. Guidelines for the management of small pulmonary nodules detected on CT scans: a statement from the Fleischner Society. Radiology 2005; 237: 395-400.

16 Haralick RM, Sternberg SR, Zhuang X. Image analysis using mathematical morphology. IEEE Trans Pattern Anal Mach Intell 1987; 9: 532-550.

17 Gurney JW, Jones KK, Robbins RA, et al. Regional distribution of emphysema: correlation of high-resolution CT with pulmonary function tests in unselected smokers. Radiology 1992; 183: 457-463.

18 Thurlbeck WM, Muller NL. Emphysema: definition, imaging and quantification. AJR Am J Roentgenol 1994; 163: 1017-1025.

19 Martelli NA, Hutchison DC, Barter CE. Radiological distribution of pulmonary emphysema. Clinical and physiological features of patients with emphysema of upper or lower zones of lungs. Thorax 1974; 29: 81-89.

20 Martinez FJ, Curtis JL, Sciurba F, et al. Sex differences in severe pulmonary emphysema. Am J Respir Crit Care Med 2007; 176: 243-252.

21 Omori H, Nakashima R, Otsuka N, et al. Emphysema detected by lung cancer screening with low-dose spiral CT: prevalence, and correlation with smoking habits and pulmonary function in Japanese male subjects. Respirology 2006; 11: 205-210.

22 Kalender WA, Rienmuller R, Seissler W, Behr J, Welke M, Fichte H. Measurement of pulmonary parenchymal attenuation: use of spirometric gating with quantitative CT. Radiology 1990; 175: 265-268.

23 Gierada DS, Yusen RD, Pilgram TK, et al. Repeatability of quantitative CT indexes of emphysema in patients evaluated for lung volume reduction surgery. Radiology 2001; 220: 448-454.

24 Moroni C, Mascalchi M, Camiciottoli G, et al. Comparison of spirometric-gated and ungated HRCT in COPD. J Comput Assist Tomogr 2003; 27: 375-379.

25 Bakker ME, Stolk J, Putter H, et al. Variability in densitometric assessment of pulmonary emphysema with computed tomography. Invest Radiol 2005; 40: 777-783.

26 Newell JD, Hogg JC, Snider GL. Report of a workshop: quantitative computed tomography scanning in longitudinal studies of emphysema. Eur Respir J 2004; 23: 769-775. 